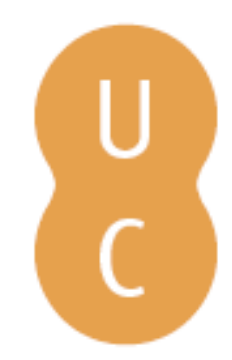

\title{
nommalina
}

\section{O turismo, o turista e o território: uma nova centralidade para a geografia?}

\author{
Autor(es): $\quad$ Cravidão, Fernanda; Nossa, Paulo \\ Publicado por: Imprensa da Universidade de Coimbra \\ URL \\ persistente: \\ URI:http://hdl.handle.net/10316.2/43498 \\ DOI: \\ DOI:https://doi.org/10.14195/978-989-26-1343-7_28
}

Accessed : $\quad$ 26-Apr-2023 15:25:27

A navegação consulta e descarregamento dos títulos inseridos nas Bibliotecas Digitais UC Digitalis, UC Pombalina e UC Impactum, pressupõem a aceitação plena e sem reservas dos Termos e Condições de Uso destas Bibliotecas Digitais, disponíveis em https://digitalis.uc.pt/pt-pt/termos.

Conforme exposto nos referidos Termos e Condições de Uso, o descarregamento de títulos de acesso restrito requer uma licença válida de autorização devendo o utilizador aceder ao(s) documento(s) a partir de um endereço de IP da instituição detentora da supramencionada licença.

Ao utilizador é apenas permitido o descarregamento para uso pessoal, pelo que o emprego do(s) título(s) descarregado(s) para outro fim, designadamente comercial, carece de autorização do respetivo autor ou editor da obra.

Na medida em que todas as obras da UC Digitalis se encontram protegidas pelo Código do Direito de Autor e Direitos Conexos e demais legislação aplicável, toda a cópia, parcial ou total, deste documento, nos casos em que é legalmente admitida, deverá conter ou fazer-se acompanhar por este aviso. 


\section{FERNANDA CRAVIDÃO}

\section{IÚCIO CUNHA}

PAULA SANTANA

\section{NORBERTOSANTOS}

(ORG.)

\section{ESPAÇOS E TEMPOS EM GEOGRAFIA}

HOMENAGEM A ANTÓNIO GAMA

IMPRENISA DÁ UNIVERSIDADE DE COIMBRA COIMBRA UNIVERSITY PRESS

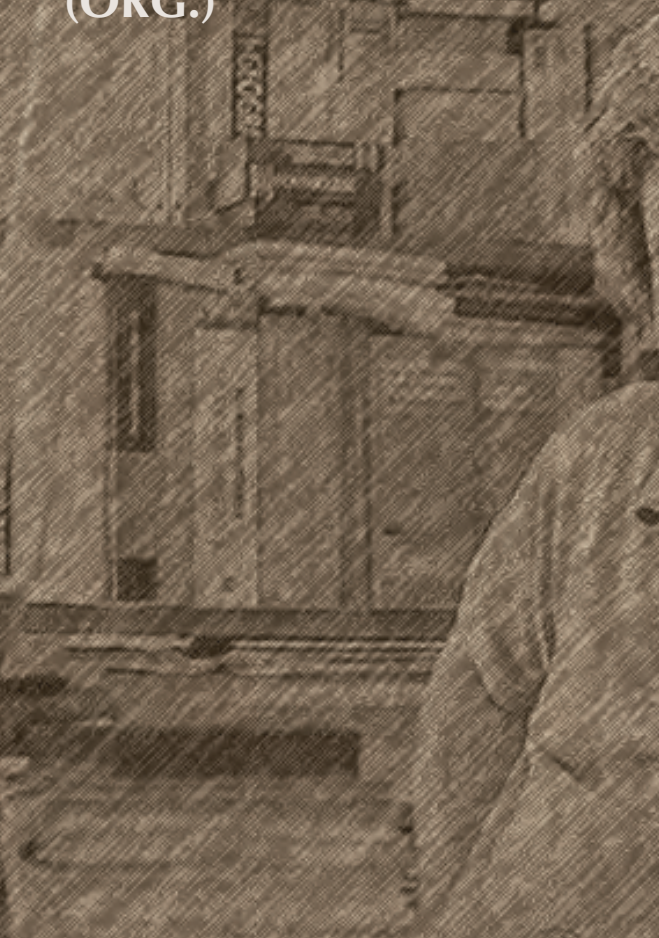




\title{
O TURISMO, O TURISTA E O TERRITÓRIO - UMA NOVA CENTRALIDADE PARA A GEOGRAFIA?
}

\author{
Fernanda Cravidão/cravidao@fl.uc.pt \\ Paulo Nossa/paulonnossa@gmail.com \\ Departamento de Geografia e Turismo \\ da Faculdade de Letras da Universidade de Coimbra \\ e Centro de Estudos de Geografia \\ e Ordenamento do Território (CEGOT)
}

\begin{abstract}
"O espaço representado não é mais o espaço, mas a imagem do espaço, ou melhor, do território visto e ou vivido"
\end{abstract}

(Raffestin, 1993: 147)

\section{Introduçáo}

Data de 1902 o que parece ser o primeiro estudo dos impactos espaciais provocados pela atividade turística. Escrito por A. Brouguier, tem como área de análise a Baviera: L'importance du tourisme en Bavière. É de resto nesta sequência, alteraçóes territoriais geradas sobretudo nas estâncias turísticas europeias ligadas a neve, que a noção de Geografia do Turismo terá sido pela primeira vez utilizada. A. L. Gomez (1988:46) escreve: "Stradner (1905) fue el introductor en la bibliografia germana especializada del termino geografia del turismo, (...) el cual, desde entonces, ha servido para designar a la rama de nuestra disciplina que se ha ocupado de analizar de una manera particular 
ciertos impactos producidos por lo que de una manera ampla pudiérmos chamar el fenómeno del ocio". A escola alemá tem de resto um papel fundamental nas primeiras reflexóes a propósito da atividade turística no território. Em 1939, Poser marca uma nova etapa, com o trabalho La place des montagnes moyennes. Neste texto, o autor reflete, quer a propósito do significado que a paisagem assume no seio da geografia do turismo quer, também, do impacto que este fenómeno gera nos territórios. Isto é, apesar de ser sobretudo a partir da década de sessenta do século xx que o fenómeno turístico inicia um processo de consolidação e estruturação, um pouco por todo o mundo, promovendo múltiplas reflexóes, onde a geografia tem um papel central, as alteraçôes que se registam vão trazer novas abordagens onde a sociologia, a antropologia, a economia ou a história cada vez mais se cruzam, com a geografia, em análises multiescalares e multidisciplinares.

As transformaçóes económicas, sociais, o desenvolvimento dos transportes, a democratização do automóvel, a consolidação das férias pagas, o reconhecimento do direito ao lazer, são alguns dos fatores que suportam, por um lado, a importância progressiva da atividade turística e por outro, as mudanças que se váo desenvolvendo e onde emergem novas relaçóes com o tempo, com o passado, com o território, com a cultura.

Se em 1950 os 25 milhôes de turistas internacionais tinham destinos quase sempre bem definidos, em que os lugares de eleiçáo tinham no sol e mar o principal produto, os quase mil milhōes no final da $1 .{ }^{\text {a }}$ década do século XXI escolhem percursos cada vez mais diferenciados onde cada destino tem o seu lugar próprio. Esta "nova forma de viajar" apela à experiência, a uma atração quase nostálgica, a uma identidade social e territorial onde se recriam novas identidades. Os sítios, os lugares, os territórios, adquirem novas dimensôes, simbólicas, afetivas. Tal como sublinham Kearns e Gesler (1998), na produção identitária e contemporânea dos lugares, devemos ter presente uma dimensão polimórfica, estratificada, que está para além das características físicas dos lugares, marcada pelas experiências sensoriais registadas (luz, som, odor, temperatura), pelas experiências preceptivas mediadas pela consciência e pela dinâmica dos valores estéticos, políticos, religiosos e históricos (inclusão, 
exclusão, agitação, quietude, medo). Neste contexto, as ligaçóes entre o turismo e os territórios parecem particularmente importantes no tecido das práticas turísticas/culturais da sociedade contemporânea. É neste sentido que as novas cumplicidades entre turista/visitante e o lugar representam, para a sociedade de hoje, um elo entre a tradição e a modernidade e por isso uma ligação em construção permanente, onde o sentido de lugar adquire uma centralidade nova.

Estas são, já, ligaçōes antigas. Quando os filhos da burguesia inglesa, no final da sua formação académica, realizavam a viagem, o "tour" que os levava a conhecer os lugares das civilizaçôes clássicas, ou as grandes referências culturais de então, como Praga ou Paris, eram os territórios que procuravam. Espaços que retratavam as relaçôes com a sociedade, com a cultura, e por isso territórios onde o material e imaterial se cruzam, se completam. Ontem como hoje.

\section{Breve percurso pelos territórios do turismo}

No século XviII Diderot escrevia que as águas mais distantes eram as que se deviam eleger pois o mais importante era a viagem. Neste percurso temporal, é certo, também, que a viagem se foi adaptando às alteraçôes sociais que ao longo do tempo têm tido como cenário quase todas as regióes do mundo. Porém, ainda, hoje a viagem continua a ter um valor simbólico.

O século Xvıı foi definitivo para a estruturação e progressiva consolidação da atividade turística mundial. Se o "Grand Tour", realizado pelos filhos da burguesia inglesa tinha um "olhar neutro" das galerias de arte, dos museus, com o Romantismo emerge "o turismo voltado para a paisagem" (URRY, 1996), valorizando progressivamente o território que se visita, onde se permanece durante algum tempo e desafiando cada vez mais essa neutralidade. O começo da institucionalização das férias tem, no final do século XIX, na Inglaterra do Norte, os primeiros trabalhadores abrangidos. A procura pelas frentes de mar vai, de modo progressivo, intensificar-se e, com o passar dos tempo, massificar-se. Ainda hoje, estes territórios ancorados à água, ao sol e à praia, constituem os 
grandes lugares de chegada para milhóes de turistas em todo o mundo. Ainda que com tempos e modos de uso e fruição diferentes.

"Bradford à beira-mar" é um dos primeiros exemplos de lugares de férias para as classes recém-integradas no mercado de trabalho inscrito na revolução industrial. "Foi aqui que as férias à beira mar (...) se tornaram uma experiência de massas durante o último quartel do século xix (Walton, 1980). O processo que se irá desenvolver tem no território o palco por excelência (Ignarra, 2003; Novelli, 2005).

As termas, herdadas do império romano, são um permanente exemplo onde a questão do território como recurso inicia um processo de apropriaçáo pelo turismo que não cessará mais. Com ciclos de esplendor e declínio, mas sempre mapeadas; nos mapas "tradicionais" e nos mapas mentais. Explorando, num primeiro momento, a água, vai, em muitos casos, passando para segundo plano. "No século XIX, na Europa, as termas, funcionam como centros urbanos elegantes, frequentados por elites, não necessariamente por motivos médicos, importava bem mais ver e ser visto na alta sociedade e valorizava-se a vertente social e cultural em detrimento do uso terapêutico das águas" (Cavaco, 2008). A terapia termal era, neste contexto, o pretexto certo para o exercício de atividades ociosas, lúdicas e desportivas, estratégia distintiva utilizada para suprir necessidades curativas que os excessos "crónicos", característicos de determinadas classes superiores, causavam nos organismos. A estada termal, sempre prolongada, marcava de modo exuberante uma independência em relação aos calendários de trabalho, funcionando como instrumento de diferenciação social que a aristocracia (e mais tarde a burguesia em ascensão) organizou para manter a distinção (Ferreira, 1994).

Baden-Baden foi, durante muitos anos, como que sala de visita da Europa de então. Esta relação, coletiva e individual, com o(s) território(s) atravessa toda a atividade turística. Modifica-se. Diversifica-se. Mas está presente.

Num rápido olhar por antigos percursos ou notas de viagem há (quase) sempre uma "marca" que os define ou identifica, tornando-os únicos: a sua geografia. É esta a motivação que leva os primeiros turistas pela Patagónia, ou os que atravessam as grandes reservas de África, ou aqueles que visitam o 
Parque de Yellowstone nas Montanhas Rochosas, ou ainda os que procuram nas Cataratas do Niágara novas sensaçôes, ou os outros que na Côte d'Azur ou na Costa do Sol começam a construir imagens de lugares que têm (nesse tempo) o clima como atração principal. (cfr. Lozato-Giotarto, 1993). Nas primeiras décadas do século xx, a procura pela classe rica da Europa do Norte situava-se, sobretudo, no sul de França - Nice e Cannes - onde permaneciam longe dos invernos rigorosos. Tratava-se de um turismo homotérmico que se esbate, progressivamente, com a emergência do turismo de sol e mar e que tem, nas estações quentes, os tempos de maior procura. (Besancenot, 1983, 1990)

Porém, de um fenómeno de elites que se deslocavam segundo uma geografia bem delimitada, transforma-se, em menos de 50 anos do século $\mathrm{xx}$, num fenómeno massificado e global. Entre os anos 50 e 60 do século xx o número de viagens duplicou, de 25 milhóes para cerca de 50 milhóes; dez anos depois ultrapassava 125 milhōes; no início dos anos noventa situava-se próximo dos 500 milhôes, para, em 2008, atingir o total de 903 milhóes prevendo a OMT, 1600 milhóes em 2030. Neste contexto e apesar da crise económica internacional, 2012 constituiu um marco na história da viagem e do turismo, atingindo o simbólico número de mil milhôes de viajantes num só ano, ao qual, em 2013, se somaram mais 52 milhôes de turistas, perfazendo um total mundial de 1087 milhôes de chegadas, $53 \%$ das quais tiveram como destino a Europa, seguidas pela Ásia e Pacífico, com 23\% dos viajantes (OMT, 2014).

\section{O Século XX - dos "novos" turismos às "novas" geografias}

A atividade turística, pelas suas próprias características, esteve sempre exposta às grandes alteraçôes sociais e económicas do século xx. Ainda que nos

primeiros anos se assista ao continuar da matriz herdada do século anterior, as mudanças de que o mundo foi protagonista vão-se retratar em todos os domínios da sociedade. A atividade turística, cada vez mais consolidada e exposta a estas alteraçốes, tem no desenvolvimento dos transportes, na melhoria do nível de vida, no aumento da esperança de vida, no aumento da escolaridade, 
na institucionalização das férias pagas, na mobilidade social, alguns do fatores principais para se desenvolver e globalizar.

Os operadores turísticos criam novos percursos, novos territórios, onde o longínquo, porque simbólico, adquire progressivamente o papel principal. Territórios que eram imaginados, faziam parte dos mapas mentais, das histórias familiares, dos percursos migratórios, estão agora ao dispor do turista.

As Ilhas do Caribe, os Estados Unidos, o Brasil ou alguns países asiáticos, passam a fazer parte de pacotes turísticos onde a imagem que é vendida vai ao encontro do imaginário de cada um e de todos.

Já em 1977 Jean Marie Miossec no texto L’image touristique comme introduction à la géographie du tourisme, chamava a atenção para os novos caminhos da atividade turística que então se começavam a delinear. Neste estudo, o autor, reflete a propósito da importância na decisão da viagem, das imagens que cada um construiu. De como as diferentes representaçôes que cada um transporta constituem suportes importantes para as escolhas de itinerários, construção de novos olhares sobre o território, definiçãao de diferentes perfis de turistas. São estes que promovem e obrigam a ofertas cada vez mais definidas e dirigidas, procurando cativar "velhos" e "novos" turistas, conferindo novas imagens a "velhos" lugares e alterando e diversificando a sua atratividade. Há novas procuras, novos perfis de turistas, novas formas de olhar e consumir o território onde o lugar assume um lugar diferente e onde a sua geografia lhe confere uma função central.

Importa dizer que a atividade turística desenvolvida, sobretudo a partir de meados de século $\mathrm{xx}$, exerceu sobre (alguns) territórios pressóes de natureza ambiental pondo em causa a sua própria sustentabilidade - física, social, económica, cultural. Numa época em que o turismo de sol e mar atraía turistas de modo sazonal, os litorais transformaram-se em enormes concentraçóes de edifícios de volumetria e arquitetura questionáveis onde, hotéis, resorts, agências de viagem e outros serviços domin(av)am. Um dos muitos exemplos é Palma de Maiorca, que viu o seu território completamente alterado."A velha Palma deixou de existir; o seu centro foi devorado por restaurantes, bares, lojas de lembranças, agências de viagem, (...) Novas conurbaçôes brotaram ao longo de 
todo o litoral. Depois que todas as árvores forem cortadas, terão de se mandar colocar arvores de plástico, para que os turistas as admirem das janelas dos seus ónibus"(Graves, 1965, citado por Urry, 1996: 88)

É neste contexto, e apesar de recente, que as práticas turísticas se modificam, se alteram, se diversificam, se consolidam, sendo certo que fazer turismo continua, ainda, a ter um valor simbólico. Náo como era entendido em meados do século xx, mas pelo que hoje significa: ainda poder económico, símbolo do exótico, sinónimo de ascensão social e cultural, mas também retratando o domínio do corpo e da mente.

Para uma parte significativa de turistas a viagem constitui, ainda, como que uma metáfora onde liberdade e domínio para além dos espaços familiares, quotidianos e da esfera do privado, são objetivos a atingir.

Neste cenário, que tem como protagonista a ultima geração do século passado, alteram-se os quotidianos, os ritmos de trabalho, os tempos de lazer assumem novas regras ou despem-se delas, buscam-se novas experiências. Há novas procuras e por essa via novas ofertas. As novas tecnologias vão impor novos ritmos e diferentes modos de aceder aos territórios. O domínio das TIC é hoje um impulsionador confirmado do Web turismo, gerando novos padróes na procura e concretização da viagem: "No novo valor do web turismo, o valor é criado através da ligaçáo a atores dentro e fora do sector do turismo em diferentes combinaçóes para criar e explorar novas oportunidades. Os mais jovens estáo muitas vezes na vanguarda de tal inovação, porque eles estáo disponíveis para cruzar as fronteiras e fazer novas ligaçôes. Como utilizadores "precoces" de nova tecnologia, os jovens são pioneiros no uso de sites de redes sociais e media móvel, à procura de informaçáo sobre viagens e compra de produtos" (WYSETC - The power of youth travel; 2011: 5).

Por esta e por outras vias, a geografia das regiōes turísticas altera-se e emergem novos espaços com novas práticas. A consciência da finitude dos territórios, a necessidade da sua conservação (Krippendorf, 1986), a segmentação e flexibilidade dos mercados turísticos começam a dar resposta às novas práticas que se traduzem em modos diferentes de os fruir. Novos consumidores, novas tecnologias, "novos" territórios, onde a competitividade é uma das palavras-chave 
(Poon, 1983). Existe uma nova cultura na relação Natureza/Ser humano onde os roteiros, o turismo cultural, de natureza, o golfe ou os desportos radicais (cfr. Santos e Cunha, 2008) constituem nichos de mercado turístico onde o desenvolvimento sustentável é uma meta (quase) conseguida.

Nesta época de mudança, o turista tem cada vez mais uma relação intimista com os lugares que visita, com os percursos que realiza, com a experiência da viagem (Netto, 2010). Há como que uma busca por territórios perdidos, por memórias geográficas.

\section{Da importância à competitividade dos(s) território(s)}

Para diversos autores (Cavaco, 2008; Cavaco e Simóes, 2009; Féris 2006; Ignarra, 2003; Netto, 2010), estes mercados criam novas ofertas em "velhos territórios” a públicos dirigidos, personalizando os consumos. Deste modo imprimem-lhe uma singularidade que lhes dá um lugar nos mapas turísticos. Os exemplos distribuem-se por todas as latitudes, respondendo a um novo padrão de turistas. Mais informados. Com maior consciência de cidadania. Novas relações com o território. Outros modos de os fruir. Buscam novas experiências em "velhos" lugares. Tal como sempre sucedeu ao longo da longa história da atividade turística e de lazer, o território responde. Adapta-se. Agora, por via das novas tecnologias do marketing, dos novos perfis de turistas, encontra novas respostas para novas procuras. (Re)inventam-se percursos, (re)constroem-se imagens há muito perdidas.

Dá-se novos usos a velhos espaços. Com outras práticas. Outros tempos de ocupação. Visitas mais curtas. Novas formas de fruição. Tudo se adapta. Durante todo o ano e para todos os turistas. Sáo inúmeros os exemplos. No Mundo, na Europa, em Portugal. Tomemos apenas alguns que mostram a capacidade, quase infinita, de como o território é recurso/produto principal.

A gastronomia é moldada e reflete os territórios (Gimenes, 2010). Dá sentido aos sabores e aos saberes. Torna-se numa experiência turística e sensorial. Onde as geografias se cruzam. Durante os séculos XVIII, XIX e princípio do XX, as 
migraçôes que se dirigem de todo o mundo para o mundo todo, levam consigo as práticas, a capacidade de adaptar produtos autóctones com os de locais de partida, encontrando novos sabores, novas modos de confecionar, ainda que a matriz seja a dos pais de origem. Sáo muitos os exemplos. Os milhóes de italianos que se dirigiram para o novo mundo levaram consigo a pizza, originária da região de Nápoles, e transformam-na num produto global. O sushi, produto de uma antiga arte culinária japonesa, vai acompanhar os fluxos migratórios que do Japão se dirigiram sobretudo para o continente americano. A difusão das técnicas de manufatura de queijos partiu, quase a medo, no século xvi da Europa mas, no século xix, chega à Austrália, América do norte e do sul.

É em cidades como Nova Iorque, Los Angeles ou S. Paulo que hoje encontramos alguns dos restaurantes que transformaram um simples prato num arte gastronómica e turística e que testemunha esta relaçáo permanente entre migração e alimentação/gastronomia. No cruzamento multicultural soube encontrar-se a singularidade que distingue cada lugar de origem. "A gastronomia constitui (ou pode vir a constituir), uma experiência turística, na medida em que oferece, a partir dos sabores e técnicas culinárias características, uma interação com o meio visitado. Ao se degustar, pode ter-se acesso a uma série de acontecimentos simbólicos que termina por revelar a história e a cultura de um grupo humano" (Gimenes, 2008).

Espaços há muito abandonados por migrações de dimensão diversa, retomam, em muitos casos, novas vivências para novas ofertas turísticas onde a experiência está cada vez mais presente. Muitas destas "novas" geografias emergem de imagens criadas por histórias familiares, por espaços perpetuados pela literatura, pelo cinema, por ligaçôes afetivas, por ligaçóes estéticas. Estes "novos" territórios de viagem vêm ao encontro desse imaginário, dando-lhe uma identificação territorial que vai começando a desenhar novos mapas. Tal como afirma Rosa Gomes (s/d) "habilmente reconvertidos (os bens culturais) são um eficaz instrumento de desenvolvimento territorial, (turístico) para além de serem elementos potenciadores de qualidade de vida, uma vez que trazem a reabilitação de espaços e a consequente oferta de novos serviços, sempre inspirados na identidade do lugar". 
É também neste contexto de mudança e competitividade territorial que o estabelecimento, por exemplo, de rotas e de redes, tem promovido a construção de itinerários, que passam pelo natural, pelo arquitetónico, atravessam o histórico, o religioso, o cinema, a música. De facto, a importância económica que a atividade turística assume, do local ao global, criou e cria expectativas que são registadas no discurso político, nos planos estratégicos de desenvolvimento, nos agentes económicos, na comunicação social, nas populaçôes. Uma rota pode reforçar o sentimento de unidade dentro da diversidade de um território. Uma rota pode ajudar a promover a coesão territorial e social e, neste sentido, o desenvolvimento. O património arquitetónico, o artesanato, a música, a gastronomia, podem constituir um guiáo que nos leve a novos percursos e a outros olhares.

Os Caminhos de Santiago, constituem um exemplo de como percursos que germinaram por motivaçôes religiosas, sobretudo durante os séculos XI e XII, jornadas ordenadas por obrigação, reganharam protagonismo convertendo-se em itinerários voluntários de conhecimento, experienciação e enriquecimento, tendo sido declarados como Primeiro Itinerário Cultural Europeu em 1987, e Património da Humanidade em Espanha e em França, respetivamente 1993 e 1998. Estes percursos fazem, agora, apelo a novas experiências onde o turista "vive e sente" a paisagem que o envolve, o território que visita, a geografia do lugar.

Num tempo em que a consciência pela preservação ambiental quase se globalizou, os espaços naturais encontraram, pela via do marketing, das novas tecnologias, do acesso à informação, novos formatos para serem fruídos. O território mítico que constitui a Amazónia é disso um exemplo.

Uma vez mais, estes lugares estão na vanguarda da diferenciação da oferta, reinventando-se numa fuga à massificação, afirmando-se como territórios singulares (Amazónia, Antártida, Galápagos...) onde (re)emerge o conceito de expedição, num misto de turismo natureza e aventura, proporcionando a pequenos grupos uma experienciação quase científica em ambiente e contexto de lazer.

Outro bom exemplo de como os territórios se adaptam às novas procuras pode ser referenciado na Nova Zelândia. Não sendo pioneiro, é um dos países onde paisagem/território tem com e na natureza uma maior envolvência com 
o "novo" turismo. O tramping tem adquirido um significado cada vez maior na captaçâo de turistas "amigos do ambiente" (Ross, 2008). É de resto nestes cenários que o turismo ligado aos espaços cinematográficos acolhe cada vez mais visitantes. Se o Senhor dos Anéis, leva "ao outro lado mundo" muitos turistas, Hollywood, constitui, também, um lugar de chegada para milhões de visitantes onde os imaginários se encontram, e se recriam cenas há muito "vividas". São centenas de restaurantes, cafés, bares, lojas, onde se reproduz o "velho oeste", o Jurassic Park ou a Guerra das Estrelas. Segundo Hanefors e Mossberg (2001) e Strauss (2003), os lugares divulgados pelo cinema podem tornar-se locais de destino turístico, já que criaram no espectador expectativas em relaçáo aos territórios que divulgam. Tudo dá sentido, ou parece dar, à viagem.

A Montanha, frequentemente imponente mas sempre frágil, desde há muito que atrai visitantes. As grandes estaçóes de turismo de neve, Aspen nas Montanha Rochosas (USA), Saint Moritz ou Andorra, entre muitas outras, foram-se massificando, gerando problemas de sustentabilidade de difícil resolução. Nestes contextos de mudança surgem novas alternativas onde a montanha é o recurso, mas as práticas turísticas alteram-se tendo como suporte a geografia desses territórios. O turismo de aventura, os circuitos pedonais, a paisagem, criam novas procuras. Novos turistas. O trekking que se pratica em muitos lugares do mundo (Peru, Argentina, Nova Zelândia ou Nepal) constitui um bom exemplo de como os operadores turísticos, moldaram velhos territórios em novos espaços. Portugal não fica alheio a este processo. Ainda que a uma outra escala, no seu território de montanha, estabelecem-se novas práticas turísticas/lazer, reconfigurando cenários envelhecidos de antigos espaços termais e sanatoriais, agora reconvertidos em elegantes centros wellness ${ }^{1}$.

Com um território topograficamente diversificado, uma frente de água privilegiada, os desportos radicais dão novas geografias aos espaços de lazer. As rápidas difusôes de informação - redes sociais, televisão, divulgaçôes em

\footnotetext{
${ }^{1}$ Combinação proposta por Dunn (1961) que conjuga a palavra wellbeing (bem-estar) com a palavra fitness (aptidão física) e que, adotando uma visão holística, propõe um conjunto de práticas orientadas para alcançar um estado de equilíbrio do corpo, espírito e mente.
} 
revistas especializadas, internet, associados a uma publicidade tecnicamente bem estudada, encarregam-se de fazer chegar a alguns grupos de população este tipo de desporto. O território nacional rapidamente entrou na lista de sítios obrigatórios de campeonatos mundiais. Vejam-se os exemplos das provas de Surf que têm lugar na Nazaré ou Peniche, e Bodyboard na Figueira da Foz" (Cravidão e Cunha, 1998). Exemplos de como é quase infinita a capacidade de criar novos interesses de procura, em velhos territórios mas sempre moldados pela sua geografia.

\section{Consideraçóes finais}

No início do século XXI o turismo reflete, também, os novos paradigmas que marcam o mundo. O global que valoriza o local. A consciência de finitude dos recursos. O saber olhar o Outro. O domínio de novas tecnologias, do marketing, da publicidade. A busca de novas experiências onde prazer, domínio do corpo e da mente se cruzam e valorizam. Nestes cenários os territórios continuam a ter um papel decisivo. As "velhas” práticas turísticas dão lugar a novos modelos de fruição que levam à (re)construção de imagens novas em "velhos" territórios. Ainda que sejam a montanha, as termas, o sol e o mar, os espaços do sagrado, os centros históricos, os espaços rurais ou paisagem, os lugares de chegada para quase mil milhóes de turistas, os novos modos de fazer turismo e os novos turistas, exigem outras experiências a que o território responde, quase sempre com novas ofertas. A montanha vai-se transformando num espaço de múltiplas funcionalidades. As termas dão lugar ao SPA's e ao wellness polarizando novos fluxos que dão lugar ao turismo de saúde e bem-estar, oferecendo serviços para todas (ou quase todas) as classes sociais. As praias vão progressivamente adquirindo novos hábitos de consumo. De verão e de inverno. De modos diferentes ao longo do dia. Os desportos ligados ao mar, os concertos promovidos por bandas musicais, encontram nestes "velhos" territórios um espaço imenso para se desenvolverem e se promoverem. Lugares de culto religioso deixam de ter calendarizaçóes rígidas e são visitados de acordo com novos ritmos de trabalho 
ou de férias, criando liturgias adaptadas aos novos ritmos do quotidiano, como é o caso da celebração da Semana Nacional das Migrações que culmina a 13 de Agosto no Santuário de Fátima.

A flexibilização da oferta permite, hoje, encontrar sempre um operador que vá ao encontro do interesse do turista. É antiga esta relação do turismo com o território com a geografia. Porém, esta ligação tem-se tornado cada vez mais forte e criativa. Não só porque o território é o palco principal mas sobretudo porque é o seu maior recurso, e aqui a geografia renova a sua centralidade.

\section{Bibliografia}

Besancenot, J. L. (1983). Les bioclimats humaines en façade méditerranée de l'Europe. Thèse d'État, Université de Dijon. 750 p.

Besancenot, J. L. (1990). Climat et Tourisme. Paris: Éditions Masson, 223 p.

Cravidão, F. (2012). Turismo, território e Cultura. Uma trilogia (sempre) em construção. Espaço e Cultura, UERJ, Rj, n.o 29, pp. 35-42.

Cravidão, Fernanda (2014). Velhos territórios: novo(s) turismo(s). In C. Costa, F. Costa Brandão \& Z. Breda (orgs.), Turismo nos Paises Lusófonos: conhecimento, estratégia e territórios. Escolar Editora, pp. 59-70.

Cravidão, F. \& Cunha, L. (2008). Notas para uma geografia dos desportos radicais em Portugal. In Norberto Santos e António Gama (coord.), Lazer - da libertação do tempo livre à conquista das práticas. UC. Coimbra, pp. 131-145.

Cravidão F. \& Santos, N. (orgs.) (2013). Turismo e cultura: destinos e competitividade. Coimbra: Imprensa da Universidade: $545 \mathrm{p}$.

Feifer, M. (1985). Going Places. Londres: Macmillan.

Ferreira, C. (1994). Os usos sociais do termalismo. Práticas, representaçóes e identidades sociais dos frequentadores das Termas da Curia. Provas de Aptidão Científica e capacidade pedagógica. Coimbra: FEUC.

Gimenes, A. (1991). As consequências da modernidade. S. Paulo: UNESP.

Gomez, A. (1988). De la Geografia del turismo al estudio de las actividades de ócio. Algunos problemas concetuales. Estudios Turisticos, Madrid, 98, pp. 43-58.

Kearns, A. \& Gesler, M. (1998). Putting Health into Place. Landscape, Identity, and Well-being. Syracuse University Press.

Krippendorf, J. (2000). Sociologia do Turismo: para uma nova compreensäo do lazer e das viagens. S. Paulo: Ed. Aleph.

Marujo. N. \& Cravidão, F. (2012). Turismo e lugares: uma visão geográfica. PASOS, Revista de turismo y património Cultural, Vol. 10, n. ${ }^{\circ} 3$, pp. 281-288. 
Miossec, J. M (1977). L'image touristique comme introduction à la géographie du tourisme. Annales de Géographie, Tomo 86, n. ${ }^{\circ} 473$, pp. 55-70.

Moreira, C. \& Santos, N. (2010). New opportunities for water environments. River Tourism and water leisure activities. In WATER and TOURISM. Lisboa: CEG, pp. 147-168

Netto, P. \& Gaeta, C. (2010). Turismo de experiência. S. Paulo: Ed. Senac.

Nossa, P. \& Dias, J. (2015). Turismo Juvenil: notas para a compreensão da oferta/procura Spring Breaker em Portugal. Cadernos de Geografia, n. ${ }^{\circ} 34$. Coimbra, pp. 21-32.

Nossa, P.; Santos; N. \& Cravidão, F. (2013). Risco e vulnerabilidade: a importância de factores culturais e sociodemográficos na interpretação e reaçáo aos perigos. In Luciano Lourenço (org.), Riscos Naturais, Antrópicos e Mistos. Homenagem ao Professor Doutor Fernando Rebelo. Dept. Geografia. Univ. de Coimbra, pp. 45-62. http://www.uc.pt/fluc/depgeo/Publicacoes/ livro_homenagem_F. Rebelo

Poon, A. (1983). Tourism, technology and competitive strategies. Oxford: CAB International.

Raffestin, C. (1993). Por uma geografia do poder. S. Paulo: Ed. Atica

WYSETC (2011). The power of youth travel. https://www.wysetc.org/research/publications/power-of-youth-travel/

UNWTO Annual Report 2013 | World Tourism Organization UNWTO

URRY, John (1996). O olhar do turista: lazer e viagens nas sociedades contemporâneas. S. Paulo: Sesc. 